\title{
Genetic Relationship of Banana at Bandarlampung City Based on The Number of Chromosome and Genom Type
}

\author{
Eti Ernawiati dan Martha Lulus Lande \\ Jurusan Biologi FMIPA Universitas Lampung, \\ Jl. Soemantri Brojonegoro, Gedung Meneng, Bandar Lampung, 35145, Lampung, Indonesia \\ *Email: eti.ernawiati@gmail.com
}

\begin{abstract}
A banana was rank 4th as food consumed by the world community after rice, wheat, and corn. Identification and characterization were important steps to explore the potential and important value of this plant. This study aims to obtain the kinship profile of banana germplasm in Bandarlampung City based on the number of chromosomes and their genome types. Characterization of banana accession is done by observing the morphological characteristics referring to 15 characters from Simmonds and Shepherd with the expected score of genomic determinants modified by Silayoi and Camchalow. The results of dendrogram analysis showed that on a scale of 20-23 obtained 2 groups of banana accessions. The first group consisted of 7 accessions of bananas, namely Kepok Kapas, Kepok Manado, Kepok Kuning, Rabig, Kepok Batu, Raja Sajen, and Pisang Batu. The second group consisted of 15 accessions, namely Kepok Abu, Horn, Thousand, Janten, Mas Kuning, Mas, Muli, Rejang, Ambon Lumut, Papan, Cavendish, Ambon Kuning, Morosebo, Rajah Sereh, and Raja Nangka. Whereas 4 accessions, namely Ambon Australia, Kepok Lebanon, Kidang and Raja Bakar, could not be analyzed for their kinship because the data collection of the banana generative phase had passed or had not yet entered the generative phase. Whereas 1 accession, namely Musa ornate, is believed to be included in the Rhodhoclamys section so that the genome type cannot be determined. Based on group analysis obtained 2 large groups at a scale distance of 20-23. At a smaller scale distance of 10 obtained a subgroup with a large number of members.
\end{abstract}

Keywords : banana, dendogram, genom, number of chromosomes

\section{PENDAHULUAN}

Masyarakat dunia menjadikan pisang sebagai bahan pangan urutan ke 4 setelah padi, gandum dan jagung. Kandungan nutriri dalam 100 gram pisang masak energi 90 kalori, tidak berkolesterol, kaya vitamin A, C, B6, mineral kalsium, kalium, dan fosfor. Jumlah nutrisi tersebut lebih dari cukup untuk memenuhi kebutuhan harian orang dewasa (Simmonds,1966) Indonesia menempati urutan ke-4 dunia sebagai negara penyedia pisang dunia, setelah India, Cina dan Brazil dengan produksi 5.6 juta ton per tahun atau $7.9 \%$ dari total produksi pisang dunia (Buletin Konsumsi Pangan, 2013). Produksi pisang nasional dari tahun $2010 \quad-2014$ cenderung mengalami peningkatan dengan pertumbuhan sebesar $8.5 \%$, tercatat sebanyak 6.862.558 ton pada akhir 2014.
Wilayah Jawa masih mendominasi produksi pisang nasional. Lampung merupakan daerah penghasil pisang terbesar di luar Jawa dengan produksi mencapai 1.481 .692 ton dengan laju pertumbuhan sebesar $36.68 \%$ jauh diatas pertumbuhan nasional. Kabupaten Pesawaran penyumbang terbesar produksi pisang di Lampung. Sedangkan kota Bandar Lampung menempati urutan ke 2 dari bawah dengan produksi hanya 518 ton (BPS dan Direktorat Jenderal Hortikultura, 2015; BPS Propinsi Lampung, 2015)

Indonesia sebagai salah satu pusat keanekaragaman pisang dunia, maka koleksi plasma nutfah pisang dan diikuti dengan identifikasi dan karakterisasi sangat penting dilakukan. Rinaldi, Mansyurdin, dan Hermanto. (2014) 
mencatat dari Valmayor et al. (1991) bahwa identifikasi kultivar pisang masih terkendala karena tingkat keragaman yang tinggi dalam hal bentuk, ukuran, buah dan karakter lainnya yang tidak sesuai dan sulit digambarkan oleh tatanaman binomial asalnya. Keragaman yang tinggi pada genotip pisang di Indonesia belum diimbangi dengan karakterisasi yang memadai. Lampung sebagai sentra pisang terbesar di luar Jawa masih jauh tertinggal langkah dari daerah lain. Rozyandra (2004), Sobir, Rozyandra, dan Darma. (2005), dan Martha, Yulianti, dan Puspitasari, (2011) telah memulai langkah menggalih potensi pisang Lampung. Kota Bandar Lampung meskipun produksi pisang sangat kecil jika dibandingkan daerah lainnya tetapi diduga memiliki tingkat keragaman genetik yang cukup tinggi. Hal ini disebabkan kota Bandar Lampung sebagai ibukota propinsi merupakan magnet yang cukup kuat untuk menarik penduduk daerah pindah ke kota (penduduk urban). Keberadan penduduk urban ini diasumsikan dapat mengintroduksi kultivar dari daerah asalnya sehingga kota Bandar Lampung kemungkinan menjadi pusat keragaman pisang Lampung bisa terjadi.

\section{METODE PENELITIAN}

Penelitian dilakukan di pekarangan warga di wilayah kota Bandar Lampung dan Laboratorium Botani Jurusan Biologi FMIPA mulai bulan Mei sampai dengan Oktober 2017. Penelitian dilaksanakan menggunakan metode eksplorasi di 12 kecamatan dari 20 kecamatan yang ada di wilayah kota Bandar Lampung. Karakterisasi aksesi pisang dilakukan dengan mengamati sifat morfologi mengacu pada 15 karakter dari Simmonds dan Shepherd (1955) dengan skor harapan penentu genom yang telah dimodifikasi Silayoi dan Camchalow (1987). Pengamatan dilaksanakan secara visual untuk karakter kualitatif dan pengukuran untuk karakter kuantitatif. Dokumentasi dilakukan untuk mendukung hasil pengamatan visual dan pengukuran.
Perhitungan dilakukan dengan memberi skor 1 jika menunjukkan karakteristik yang sama denan Musa acuminate dan skor 5 jika sama dengan Musa balbisiana. Karakteristik yang berada diantara keduanya diberi skor sesuai tingkatannya, skor 2 yaitu jika lebih mirip Musa acuminate, skor 3 jika diantara keduanya dan skor 4 jika mirip Musa balbisiana. Pendugaan tipe genom dilakukan berdasarkan skor penentu kelompok genom, skor dari masing-masing aksesi selanjutnya djumlahkan dan dicocokkan dengan skor harapan kelompok genom, seperti tertera pada table di bawah ini:

Tabel 2. Rentang skor harapan kelompok genom berdasarkan karakter morfologi pisang

\begin{tabular}{lc}
\hline Kelompok Genom & Jumlah skor \\
\hline AA / AAA & $15-25$ \\
AAB & $26-46$ \\
AB / AABB & $47-49$ \\
ABB & $59-63$ \\
ABBB & $67-69$ \\
BB / BBB & $70-75$ \\
\hline
\end{tabular}

(Silayoi dan Camchalow, 1987)

Sedangkan jumlah kromosom ditentukan melalui pengamatan mikroskopis menggunakan metode squash yang telah dimodifikasi dari Gunarso (1996), dan pewarnaan menggunaakan metode yang telah dimodifikasi oleh Yulianty et al. (2006). Anakan pisang dengan tinggi antara 15 - $40 \mathrm{~cm}$ ditumbuhkan pada media pasir sampai tumbuh akar sekunder. Pemotongan ujung akar sekunder sepanjang $3-5 \mathrm{~mm}$ dari cabang akar primer bagian bawah dilakukan pada pukul 08.00 WIB. Potongan akar kemudian direndam dalam para-diChlorobenzene (PDB) jenuh selama 2 jam pada suhu $10^{\circ} \mathrm{C}$. Setelah itu akar dibilas dengan akuades sebanyak 3 kali dan difiksasi dalam larutan Carnoy selama 3 jam pada suhu $30^{\circ} \mathrm{C}$ kemudian dikeringkan menggunakan tisu. Karakter organ vegetatif dan organ generatif yang diamati disajikan dalam tabel di bawah ini: 
Tabel 1. Karakter organ vegetatif dan organ generatif pisang yang diamati untuk`membedakan genom

\begin{tabular}{|c|c|c|c|}
\hline No & Organ Tanaman & Musa acuminate (genom A) & Musa balbisiana (genom B) \\
\hline \multicolumn{4}{|c|}{ Vegetatif } \\
\hline 1 & $\begin{array}{l}\text { Warna batang } \\
\text { semu }\end{array}$ & $\begin{array}{l}\text { Terdapat bercak coklat tua atau } \\
\text { hitam dan tampak jelas }\end{array}$ & $\begin{array}{l}\text { Bercak tidak jelas bahkan } \\
\text { tidak ada }\end{array}$ \\
\hline 2 & Tangkai Daun & $\begin{array}{l}\text { Tepi tangkai daun tegak atau } \\
\text { mendatar, bersayap, bagian } \\
\text { bawah tidak mememluk batang } \\
\text { semu }\end{array}$ & $\begin{array}{l}\text { Tepi tangkai daun } \\
\text { berlekatan membentuk } \\
\text { kanal, tidak bersayap, } \\
\text { bagian bawah memeluk } \\
\text { batang semu }\end{array}$ \\
\hline 3 & Tangkai tandan & $\begin{array}{l}\text { Biasanya terdapat rambut halus } \\
\text { (berbulu) }\end{array}$ & Licin, tidak berbulu \\
\hline 4 & Tangkai buah & Pendek & Panjang \\
\hline \multicolumn{4}{|c|}{ Generatif } \\
\hline 5 & $\begin{array}{l}\text { Bakal biji per } \\
\text { lokus }\end{array}$ & $\begin{array}{l}\text { Dua baris teratur dalam setiap } \\
\text { lokus }\end{array}$ & $\begin{array}{l}\text { Empat baris tidak teratur } \\
\text { dalam setiap lokus }\end{array}$ \\
\hline 6 & $\begin{array}{l}\text { Ratio } \\
\text { (panjang/lebar) } \\
\text { braktea }\end{array}$ & Biasanya tinngi $\geq 0.28$ & Biasanya rendah $\leq 0.30$ \\
\hline 7 & Keadaan braktea & $\begin{array}{l}\text { Menggulung ke belakang setelah } \\
\text { terbuka }\end{array}$ & $\begin{array}{l}\text { Braktea terangkat tetapi } \\
\text { tidak menggulung }\end{array}$ \\
\hline 8 & Bentuk braktea & $\begin{array}{l}\text { Lanset, oval, sempit meruncing } \\
\text { tajam }\end{array}$ & $\begin{array}{l}\text { Oval, lebar, tidak meruncing, } \\
\text { tumpul }\end{array}$ \\
\hline 9 & Ujung Braktea & Runcing & Tumpul/membulat \\
\hline 10 & Warna braktea & $\begin{array}{l}\text { Merah, ungu kusam atau kuning } \\
\text { bagian luar; pink, ungu kusam } \\
\text { atau kuning bagian dalam }\end{array}$ & $\begin{array}{l}\text { Ungu kecoklatan bagian } \\
\text { luar, merah tua atau terang } \\
\text { bagian dalam }\end{array}$ \\
\hline 11 & $\begin{array}{l}\text { Laju warna } \\
\text { (pemudaran } \\
\text { warna) braktea }\end{array}$ & $\begin{array}{l}\text { Braktea bagian dalam memucat } \\
\text { menguning kearah pangkalnya }\end{array}$ & $\begin{array}{l}\text { Braktea bagian dalam } \\
\text { berwarna seragam mulai } \\
\text { ujung sampai pangkal }\end{array}$ \\
\hline 12 & Bekas braktea & Jelas & Kurang jelas \\
\hline 13 & $\begin{array}{l}\text { Tepal bebas dari } \\
\text { bunga jantan }\end{array}$ & $\begin{array}{l}\text { Bergerigi kasar sampai halus di } \\
\text { bawah ujung (apeks) }\end{array}$ & $\begin{array}{l}\text { Jarang bergerigi di bawah } \\
\text { ujung }\end{array}$ \\
\hline 14 & $\begin{array}{l}\text { Warna bunga } \\
\text { jantan }\end{array}$ & Putih gading & $\begin{array}{l}\text { Bersemu merah hingga } \\
\text { merah jambu }\end{array}$ \\
\hline 15 & Warna stigma & Jingga atau kuning terang & $\begin{array}{l}\text { Gading, kuning pucat atau } \\
\text { pink pucat }\end{array}$ \\
\hline
\end{tabular}

Ujung akar selanjutnya dimaserasi dalam larutan $\mathrm{HCl} 1 \mathrm{~N}$ selama 1 menit pada suhu $30^{\circ} \mathrm{C}$. Kemudian akar direndam dalam larutan pewarna acetic-orcein $2 \%$ selama 3 jam. Ujung akar yang telah diwarnai selanjutnya diletakkan di atas gelas objek dan ditutup dengan gelas penutup. Sediaan ditekan dengan lembut menggunakan alat tumpul (ujung tumpul pensil) sampai terlihat menyebar dengan baik. Pengamatan dilakukan terhadap sepuluh sel dalam tahap prometafase dari akar yang berlainan. Preparat yang baik dipotret menggunakan kamera digital selanjutnya dipindai dan diperbesar dikomputer untuk menentukan jumlah kromosom. Dendogram profil kekerabatan aksesi pisang yang diperoleh berdasarkan tipe genom dan jumlah kromosom dianalisis kelompok hierarchical Cluster menggunakan program SPSS 16.

\section{HASIL DAN PEMBAHASAN}

Hasil ekplorasi di pekarang penduduk di 12 kecamatan dari 20 kecamatan yang ada di wilayah kota Badar Lampung diperoleh plasma nutfah pisang sebanyak 27 aksesi dari dua seksi dalam genus Musa, yaitu 26 aksesi termasuk seksi Eumusa dan 1 aseksi diduga termasuk seksi Rhodhoclamys. Kelompok genus Eumusa terdiri dari Musa acuminate (tipe genom A) mencakup 9 aksesi, Musa paradisiaca (tipe genom $\mathrm{AB}$ ) mencakup 10 aksesi, Musa balbisiana (tipe genom B) mencakup 3 aksesi, dan 4 aksesi pisang lainnya tidak dapat ditentukan tipe genomnya dikarenakan saat pengambilan data fase generatif pisang telah lewat atau belum memasuki fase generatif. Namanama aksesi pisang diperoleh melalui 
wawancara dengan warga pemilik pekarangan (kebun). Hasil pengamatan jumlah kromosom pada ke 27 aksesi pisang didapatkan jumlah kromosom $2 \mathrm{n}=$ 22 sebanyak 6 aksesi, $2 n=33$ sebanyak 19 aksesidan $2 n=44$ sebanyak 2 aksesi.

Profil hubungan kekerabatan 22 aksesi pisang asal kota Bandar Lampung berdasarkan analisis cluster dari 15 karakter penentu tipe genom dan 1 karakter jumlah kromosom dapat dilihat pada Gambar 1. Berdasarkan dendogram, pada jarak skala 20-23 diperoleh 2 kelompok aksesi pisang. Kelompok pertama, terdiri dari 7 aksesi pisang, yaitu Kepok Kapas, Kepok Manado, Kepok
Kuning, Rabig, Kepok Batu, Raja Sajen, dan Pisang Batu. Kelompok kedua, mencakup 15 aksesi, yaitu Kepok Abu, Tanduk, Seribu, Janten, Mas Kuning, Mas, Muli, Rejang, Ambon Lumut, Papan, Cavendish, Ambon Kuning, Morosebo, Rajah Sereh, dan Raja Nangka. Sedangkan 4 aksesi, yaitu Ambon Australi, Kepok Libanon, Kidang dan Raja Bakar tidak dapat dianalisis hubungan kekerabatannya dikarenakan saat pengambilan data fase generatif pisang telah lewat atau belum memasuki fase generative. Sedangkan 1 aksesi yaitu Musa ornate diduga termasuk dalam seksi Rhodhoclamys sehingga tidak dapat ditentukan tipe genomnya.

HIERARCHICAL CLUSTER ANALYSIS

Dendrogram using Single Linkage

Rescaled Distance Cluster Combine

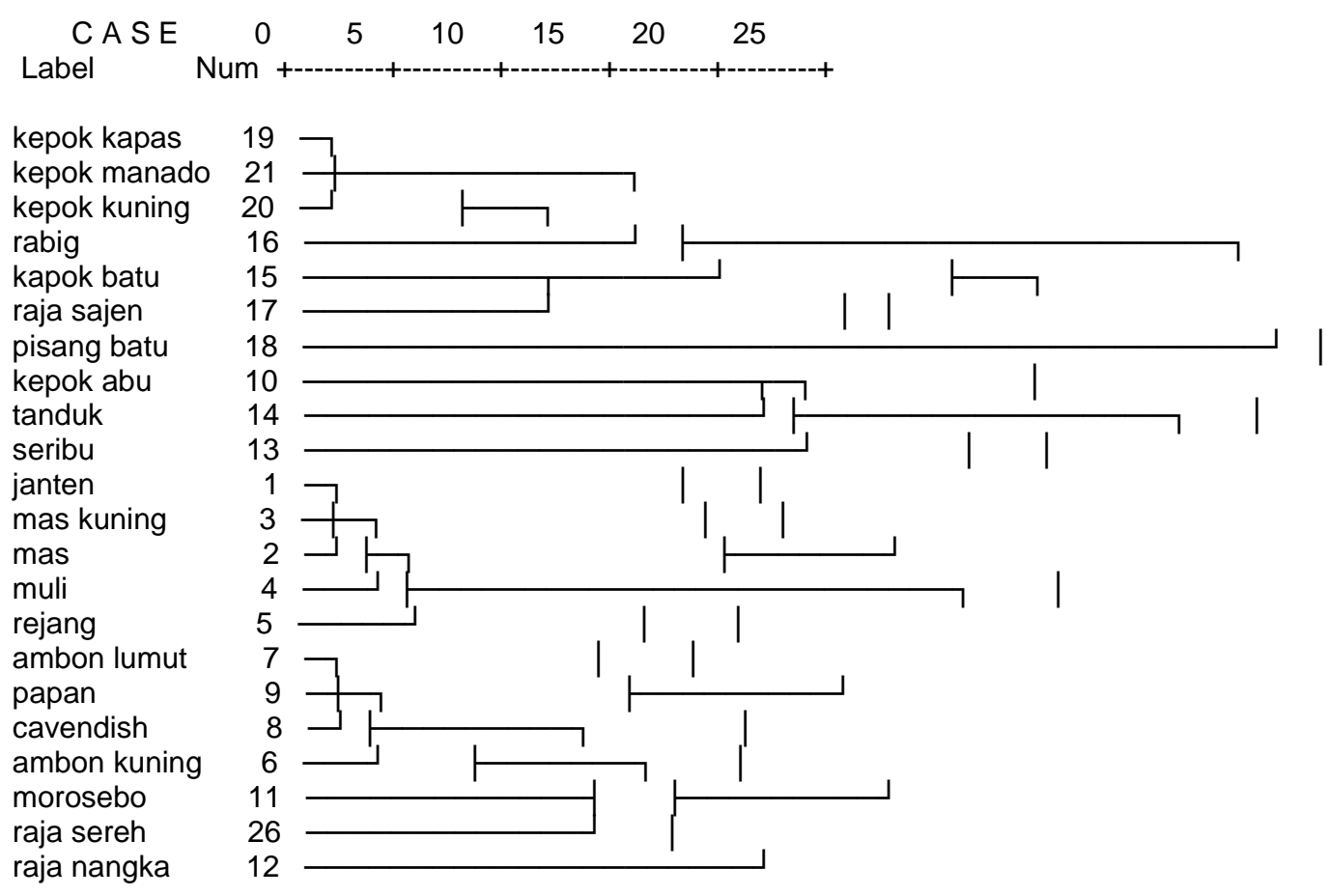

Gambar 1. Dendogram Plasma Nutfah Pisang Asal Kota Bandar Lampung Berdasarkan Tipe Genom dan Jumlah Kromosom

Kelompok pertama, pada jarak skala 10 dapat dibagi ke dalam 2 kelompok, yaitu subpertama-1 terdiri dari 4 aksesi (Kepok Kapas, Kepok Manado, Kepok Kuning, Rabig), dan subpertama-2 terdiri dari 3 aksesi (Kepok Batu, Raja Sajen, Pisang Batu). Sedangkan kelompok kedua, pada jarak skala 15 dapat dibagi lagi menjadi 2 subkelompok, yaitu subkedua-1 terdiri dari 3 aksesi (Kepok Abu, Tanduk, Seribu), dan subkedua-2 terdiri dari 12 aksesi. Selanjutnya subkedua-2 terpecah menjadi 3 kelompok pada jarak skala 10. Subkedua-2.1 beranggotakan pisang janten, mas kuning, mas, muli, dan rejang, subkedua-2.2 terdiri dari pisang ambon lumut, papan, Cavendish, dan ambon 
kuning, subkedua-2.3 meliputi pisang morosebo, raja sereh dan raja nangka. Aksesi pisang yang tercakup dalam kelompok yang sama artinya memiliki hubungan kekerabatan (Rahmawati dan Hayati, 2013). Analisis kelompok ini tidak terlalu akurat untuk menggambarkan hubungan kekrabatan dikarenakan tidak diperoleh derajat kemiripan (koefisien similiritas) antar aksesi pisang yang dianalisis.

\section{KESIMPULAN}

Tipe genom aksesi pisang yang dikumpulkan dari kota Bandar Lampung terdapat 3 tipe genom, yaitu A (Musa acuminate), B (Musa balbisiana), AB (Musa paradisiaca). Jumlah kromosom dari aksesi pisang yang terkoleksi adalah $2 n=22$ (diploid), $2 n=33$ (triploid), dan $2 n=44$ (tetraploid). Hubungan kekerabatan aksesi pisang berdasarkan analisis kelompok diperoleh 2 kelompok besar pada jarak skala $20-23$. Kemudian pada jarak skala yang lebih kecil yaitu 10 diperoleh subkelompok dengan jumlah anggota yang besar.

\section{DAFTAR PUSTAKA}

BPS dan Direktorat Jenderal Hortikultura. (2015). Produksi Pisang Menurut Propinsi (2010 - 2014). Jakarta.

BPS Propinsi Lampung. (2015). Produksi Tanaman Sayuran dan Buahbuahan propinsi Lampung 2014. No. Publikasi 18531.1503, ISSN: 2085-9066

Buletin Konsumsi Pangan. (2013). Pisang. Pusat Data dan Sistem Informasi Pertanian, 4(3), 23 - 31.
Gunarso, W. (1996). Sitogenetika. Bogor: Institute Pertanian Bogor.

Martha, L.L, Yulianty dan R. Puspitasari. (2011). Keanekaragaman Tanaman Pisang (Musa spp.) di Kabupaten Pasawaran Propinsi Lampung. Diakses dari http://mail.fmipa.ac.id./index.php/id/bi osains $/ 188$

Rahmawati, M. Dan E. Hayati. (2013). Pengelompokan Berdasarkan Karakter Morfologi Vegetatif Pada Plasma Nutfah Pisang Asal Kabupaten Aceh Besar. Jurnal Agrista, 17(3), 111 -118.

Rinaldi, R., Mansyurdin dan C. Hermanto. (2014). Pendugaan Ploidi dan Kekerabatan Beberapa Aksesi Pisang Hasil koleksi Balitbu Tropika Solok. Jurnal Sainteks, 6(1), 17-23.

Rozyandra, C. (2004). Analisis Keanekaragaman Pisang (Musa spp.) Asal Lampung (Skripsi). Bogor: Departemen Budidaya Pertanian, Fakultas Pertanian IPB.

Silayoi, B. and Chomchalow. (1987). Cytotaxonomic and morphological studies of Thai banana cultivars. In: Persley, G.J. and De Langhe, E.A., Eds., Proc. Banana and Plantain Breeding Strategies. ACIAR Proc. Canberra, 21.

Simmonds, N.W. and K. Shepherd. (1955). Bananas. London: Longmans.

Sobir, C. Rozyandra, dan K. Darma, (2005). Studi Keragaman Morfologi Aksesi Pisang Koleksi dari Kabupaten Lampung Selatan. Floribunda, 3(1), 1-28. 

